\title{
Dimitris Tsamatsoulis* \\ Prediction of cement strength: analysis and implementation in process quality control
}

\begin{abstract}
The main purpose of the present article is to develop mathematical models predicting cement strength at 28 days based on early strength as well as on physical and chemical characteristics of cement types investigated. In parallel, a relatively extended analysis of a series of existing models is performed. Static and movable time horizon models have been built and implemented to real industrial conditions for the long-term. These tools are applied in conjunction with a proportional-integral controller regulating 28 days strength around a target. Performance of the models is investigated using typical statistical analysis. The implementation of these techniques in daily quality control has been demonstrated as an important factor of quality improvement by maintaining a low variance of 28 days strength.
\end{abstract}

Keywords: cement strength; mathematical models; process quality control.

*Corresponding author: Dimitris Tsamatsoulis, Halyps Building Materials S.A., Italcementi Group, 17th KIm Nat. Rd.

Athens - Korinth, 19300, Aspropyrgos, Greece,

e-mail: d.tsamatsoulis@halyps.gr

\section{Introduction}

The development of cement compressive strength as a consequence of clinker characteristics and of physical and chemical properties of cement constitutes one of the most critical issues in the field of product design and its quality control. The traditional 28 days strength of mortar is considered as a sufficient indicator of overall quality of the product. All the norms and especially the norm applied in Europe, EN 197-1, apply specifications on this cement characteristic, concerning low and high strength limits. The manufacturer is obliged to respect these limits. The stability of cement quality is mainly characterized by the variance of 28 days strength around a predefined target.

With regard to quality data of cement and concrete, control charts are frequently applied to the results of 28 days compressive strength [1-4], and depending on their position respective actions are taken so that strength is maintained near to a desired target. A first disadvantage of this methodology is that the delay of 28 days of receiving results is long enough and probably the reasons causing strength divergence have already disappeared. A second drawback related to the delay of measuring process is that if the producer does not undertake any action during this period, lots of cement outside of specifications will probably be produced. In the case of absence of separate facilities to stock the uncontrolled cement quantities, a quality accident will happen. The following practices of avoiding low strength results are usually implemented: (1) conservative cement compositions and (2) empirical estimation of 28 days strength according to early strength results, based on past experience. The first action results in a higher cement cost, whereas the second action in an increase of strength variance due to the empirical approach.

The main purpose of the present study is to develop various models predicting 28 days compressive strength. The resulting tool is constantly applied in Halyps Cement Plant in the long-term. This article is structured as follows: a brief description of the cement production process is provided in the first section. The basic chemical moduli characterizing clinker quality are also referred to. The second section contains a summary of existing models relating cement strength with its chemical and physical characteristics. The proposed predicting models are developed in the next two sections. The implementation of the models is analyzed in the last section.

\section{Cement production processes}

Cement quality is primarily characterized by its stability concerning compressive strength in mortar and concrete. The main factors influencing the variability of cement strength are [5]:

- clinker activity,

- cement composition,

- cement fineness.

Clinker activity depends on mineral composition, free lime content and conditions of clinker formation. These characteristics are a function of the fineness and chemical 
composition of the feed to the kiln raw meal. The first parameter is regulated during grinding of the raw meal. Variation of the second parameter is related to deviations of the raw meal quality at the mill outlet and mixing ratio of the homogenizing silo.

\subsection{Raw meal production}

A simplified flow sheet of a closed raw meal grinding circuit is demonstrated in Figure 1. Raw materials limestone, clay, corrective materials - are alimented to the system through three weight feeders. The fresh feed enters the crusher and then goes into the separator. The fine outlet of the separator goes through air slides to the homogenizing silo, while the coarse return is fed to the ball mill for final grinding. The mill outlet feeds the separator through the recycling elevator. The material in the mill and in the classifier are dried and dedusted by hot gas flow.

As critical parameters for mill operation and quality regulation of the produced raw meal, the following can be considered: (1) gases flow rates; (2) gas temperature after the mill and after the separator; (3) underpressure after the mill; and (4) secondary speed of the separator, regulating raw meal fineness. Tubular ball mills and vertical ones are used for raw meal grinding [6].

\subsection{Clinker production}

A typical rotary kiln (RK) circuit for clinker production is demonstrated in Figure 2. The raw meal, originating from the homogenizing silo, is introduced to the twin cyclones and while descending to the kiln it is heated by exchanging heat with the exhaust gases.
The basic parameters concerning kiln operation and quality of the produced clinker are: (1) raw meal and fuel quality; (2) fuel quantity; (3) pressures and temperatures in the cyclones string; (4) $\mathrm{CO}$ and $\mathrm{O}_{2}$ content of the exhaust gases in the kiln outlet; (5) clinker free lime; and (6) cooler operation.

\subsection{Proportioning moduli and clinker minerals}

The proportioning moduli are used to indicate quality and activity of the raw materials, raw meal and clinker in order to regulate them properly. For main oxides, the following abbreviations are commonly used in the cement industry: $C=\mathrm{CaO}, \mathrm{S}=\mathrm{SiO}_{2}, A=\mathrm{Al}_{2} \mathrm{O}_{3}, F=\mathrm{Fe}_{2} \mathrm{O}_{3}$. The main moduli characterizing the raw meal and the corresponding clinker are [5]:

$$
\begin{gathered}
\text { Lime saturation factor }(L S F)=\frac{100 \times C}{2.8 \cdot S+1.18 \cdot A+0.65 \cdot F} \\
\text { Silica modulus }(S M)=\frac{S}{A+F} \\
\text { Alumina modulus }(A M)=\frac{A}{F}
\end{gathered}
$$

Achievement of a stable clinker quality needs regulation of some or all of these moduli. In equilibrium conditions and for rapid cooling of the clinker, oxides produce the subsequent mineral phases, which constitute the potential clinker composition [7].

$$
\begin{gathered}
C_{3} S=4.07 \cdot\left(C-\mathrm{CaO}_{f}\right)-7.6 \cdot S-6.72 \cdot A-1.43 \cdot F-2.85 \cdot \mathrm{SO}_{3} \\
C_{2} S=2.87 \cdot S-0.754 \cdot C_{3} S \\
C_{3} A=2.87 \cdot S-1.69 \cdot F
\end{gathered}
$$

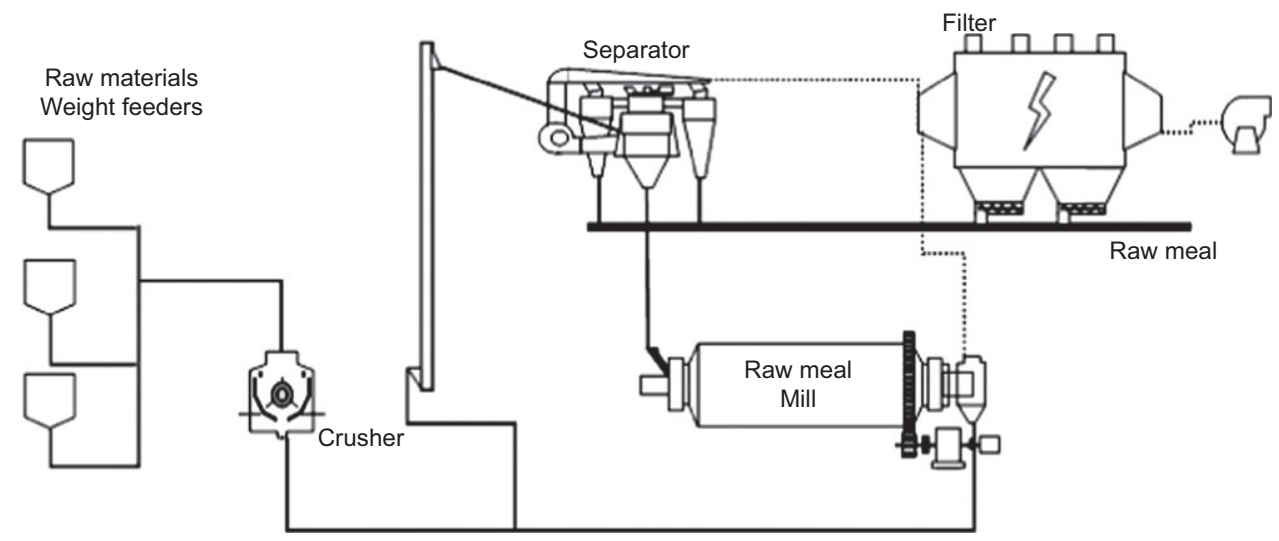

Figure 1 Flow chart of raw meal production. 


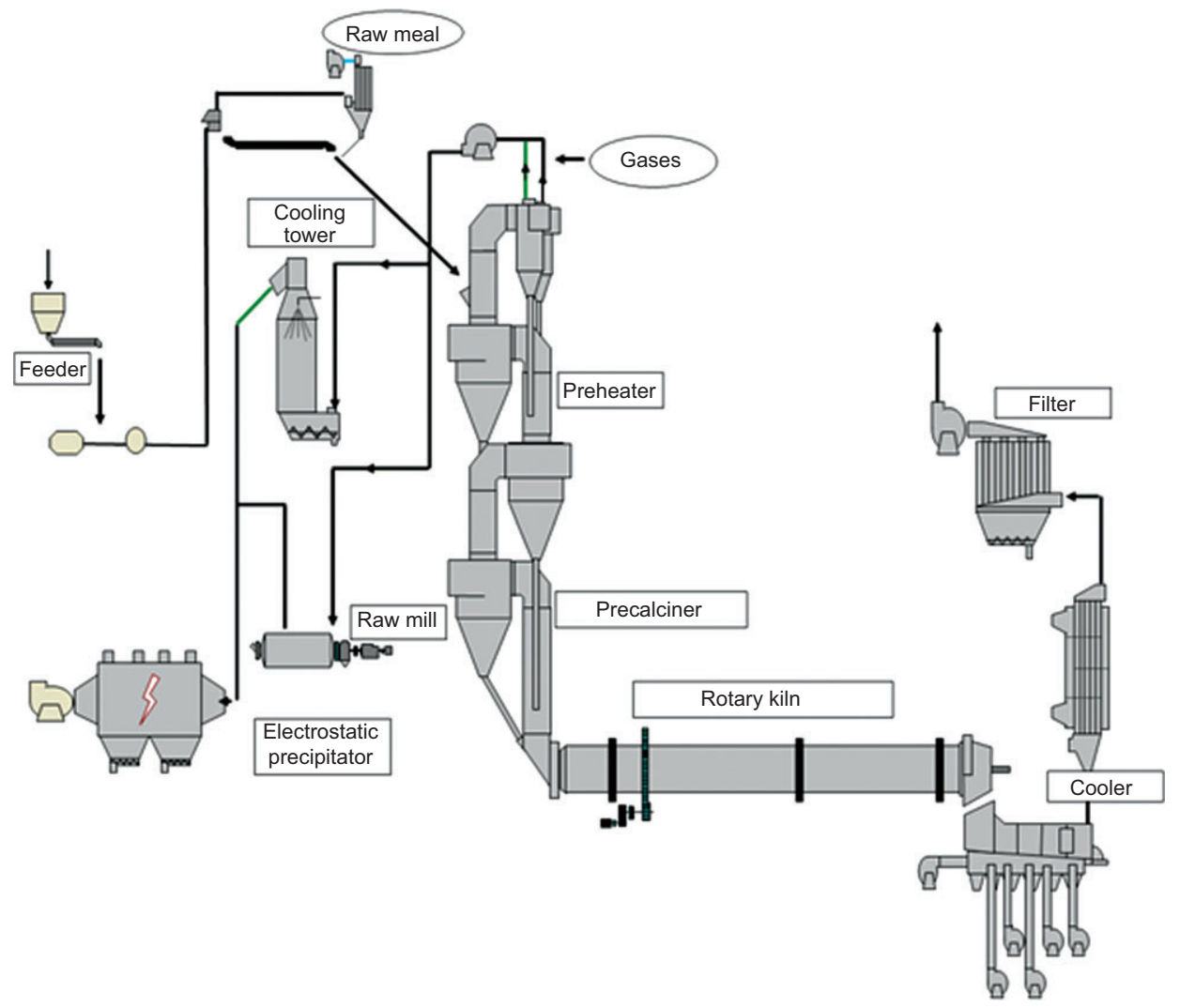

Figure 2 Rotary kiln for clinker production.

$$
C_{4} A F=3.04 \cdot F
$$

where $C_{3} S=$ alite, $C_{2} S=$ belite, $C_{3} A=$ tri-calcium aluminate, $C_{4} A F=$ ferrite, $\mathrm{CaO}_{f}=$ free lime.

\subsection{Grinding process of cement}

A simplified flow sheet of the grinding process in a ball cement mill (CM) is presented in Figure 3. All the basic elements of a closed grinding system are included, i.e., the separator, the cyclones and the dedusting filter. In a closed grinding system the basic parameters related to the installations are the following: (1) ball mill: dimensions, type of internal lining, total load of grinding media, size distribution of the balls and type of the diaphragms. (2) Auxiliaries: separating efficiency according to separator technology, filter type and dedusting efficiency, maximum gas flow rate through the system fan.

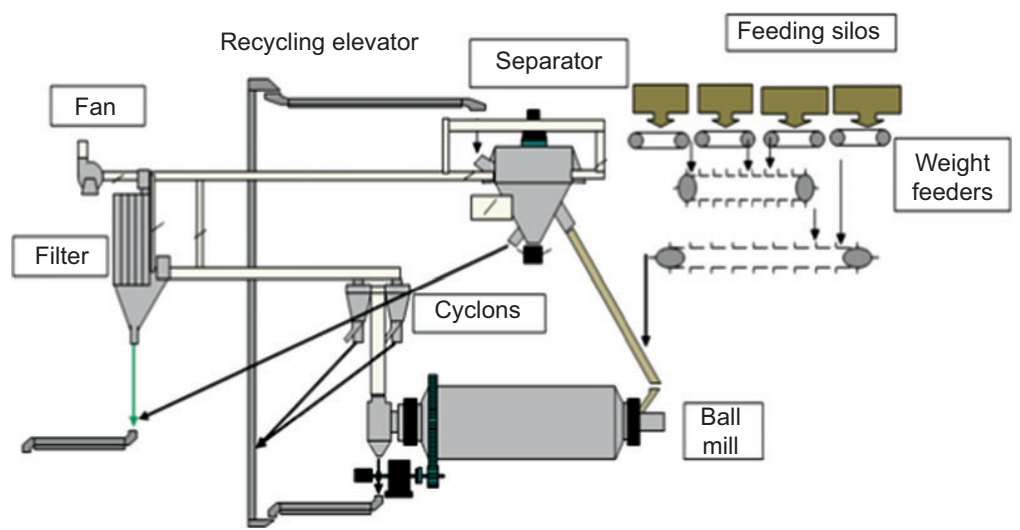

Figure 3 Closed circuit grinding system. 
Critical operating parameters related to installation productivity and product quality are the following: (1) accuracy of the weight feeders; (2) cement mill motors power; (3) gas flow rate through $\mathrm{CM}$; (4) power of the recycling elevator; (5) mass flow rate of the separator return; (6) speed of the separator; (7) gas flow rate through the separator; and (8) pressure drop in the filter. The possibility of co-grinding of more than one main component - except for the clinker - according to the norm EN 197-1, imposes the installation of more than two feeders. Additionally, a stricter control of the production process is necessary, so that a stable product quality can be maintained.

\section{Review of previous research}

Several studies describe numerous modeling techniques. Depending on the degree of complexity and data availability, different models select as inputs some of the subsequent physical, chemical and mechanical characteristics of cement and clinker: fineness, clinker mineral compounds, content of main oxides, cement composition and early cement strength. Modeling is based on linear or non-linear regression of existing data, fuzzy logic or neural networks.

Lee [5], in his historical book "The Chemistry of Cement and Concrete", referred past attempts to correlate cement properties with clinker mineral composition. The function is described by linear Eq. (8):

$$
P=a \cdot C_{3} S+b \cdot C_{2} S+c \cdot C_{3} A+d \cdot C_{4} A F
$$

where $P$ represents the value of cement property, e.g., compressive strength, at a given time. Coefficients $a, b$, $c$ and $d$ correspond to the differential contribution of $1 \%$ increase of $C_{3} S, C_{2} S, C_{3} A$ and $C_{4} A F$, respectively. According to Lee, the extent to which strength can be treated as a linear function of minerals is uncertain. The contributions to strength of the four minerals derived from different and independent data are very variable. The main conclusion is that $C_{3} S$ mainly contributes to strength measured up to 28 days, whereas $C_{2} S$ from 28 days onwards. The function between strength and fineness has also been investigated by Lee, revealing that 1 day strength is more or less a linear function of the specific surface; whereas at longer ages, strength is influenced by the shape of particle size distribution.

Odler, in 1991 [8], presented a review of existing correlations between cement strength and basic factors related to physical and chemical properties of clinker and cement, cement composition and curing conditions.
The factors investigated were as follows: (1) clinker phase composition; (2) clinker minor constituents and especially the effect of alkalis; (3) clinker structure and size and shape of alite crystals; (4) sulfates; (5) composite cements and particularly the impact of blast furnace slag and pozzolane; (6) cement fineness; (7) hydration time and temperature and degree of hydration; and (8) porosity and pore structure of cement mortars. Odler has investigated the possibilities of deriving an equation to estimate cement strength, taking into account all the above factors. He concludes that final strength of cement is determined by two main parameters: (1) cement binding capacity and (2) cement past porosity.

Sideris [9] proposed a cement hydration equation to quantitatively describe the progress of hydration. A method is suggested based upon the hydration proposition, for the determination of compressive strength of mortars and concrete for any age based on two compressive strength results. De Siqueira Tango [10] presented an extrapolation method for compressive strength prediction of cement products. The formula for predicting late age (e.g., 28 days) strength, for a given set of involved ages (e.g., 28, 7 and 2 days) is normally a function only of the two earlier ages' (e.g., 7 and 2 days) strengths. He states that this equation is independent of materials variations, including cement brand, and is also easy to use graphically.

Tsivilis and Parissakis [11] developed a regression model for the prediction of Portland cement compressive strength after 2, 7 and 28 days where the importance of chemical, mineralogical and fineness factors was pointed out. They concluded that fineness mainly affects early strength, while chemical and mineral cement composition contributes to strength development after 7 and 28 days. A similar multiple linear regression model has been developed by Kheder et al. [12], where an accelerated testing of compressive strength has also been utilized. In case the linear model was not sufficient, logarithms of the independent variables were introduced. Very similar modeling has also been performed by Abd et al. [13]. To predict compressive strength of Portland pozzolane cement, Kostogloudis et al. [14] developed a logarithmic model using standard statistical analysis tools. The authors refer the usefulness of the model to the cement industry due to its ability to predict cement strength development, only 2 days after its production. Apparently, this is valid for the studied range of clinker quality and cement composition. The clinker mineral phases are utilized in all these models [11-14], despite the variability of the contribution of each one of them. Sufficient accuracy of the predictions can be explained from the narrow range of variation of the phase, permitting additivity of their impact. 
Clinker mineralogy as a structural element of the formulae is also utilized in [15-18]. Relis et al. [15] used a time sequence dynamic correction procedure to improve model accuracy, which, except for contents of clinker phases, contained as additional inputs: cement $\mathrm{SO}_{3}$, fineness and water-to-cement ratio. García-Casillas et al. [16] applied statistical methods to build their model. They state that the proposed model provides the opportunity to predict compressive strength in a short time and this can save cost and make a competitive advantage in the cement production market. Svinning et al. $[17,18]$ used X-ray diffraction instrumentation to more accurately measure clinker phases. They claim that their prediction can be utilized to design a cement product achieving a predefined strength target.

Mechling et al. [19] used a power law model to estimate 28 days compressive strength of cement pastes using the following as parameters: a coefficient $k$ and an exponent $b$. To calibrate the model coefficients, they tested eight cements from six different cement plants. The mathematical treatment of the results made it possible to connect parameter $k$ to the $C_{3} S$ rates of the clinker. Phatak and Deshpande [20] implemented the dimensional analysis method for predicting 28 day compressive strength of cements. They incorporated the modified BuckinghamPi theorem to formulate the model by using only two experimental results. They built a trial-and-error procedure to generate dimensional analysis formulation, wherein one of the experimental data sets, called the control point, generates the dimensional analysis equation, whereas the other data set, the check point, is used to validate the already formed equation. Empirical models to predict compressive strength based on the water-to-cement ratio [21] and on the Knudsen equation [22] have also been derived.

Tsamatsoulis [23] studied the kinetics of cement strength development using different cement and aggregate types. The developed deterministic model was based on the following data: composition of cement, mineral composition of clinker, cement fineness, early, standard and long-term strength and aggregates nature. The parameters of the model are constituted by: (1) hydration rates of the mineral phases of clinker that are a function of cement fineness and follow first order kinetics and (2) contribution of each phase to cement strength. To estimate the model parameters, data of three industrially produced cement types as well as siliceous and calcareous aggregates have been utilized. The effect of clay, sometimes existing in the aggregates, is also investigated and incorporated in the mathematical treatment.

Another trend of modeling in the field of cement strength prediction is the usage of fuzzy logic and neural networks [24-30]. Gao [24], in 1997, presented a fuzzy logic procedure of predicting cement strength and he compared the results with the ones computed from regression methods. Akkurt et al. [25] utilized genetic algorithms and artificial neural network (ANN) models. Plant data were collected for 6 months. The values of chemical and physical properties of the samples were used in model construction and testing. Owing to the limited data range used for training, the prediction results were good only within the same range. In addition to neural network techniques, Akkurt et al. [27] used fuzzy logic to develop their strength prediction model. The input variables of alkalis, specific surface, $\mathrm{SO}_{3}$ and $\mathrm{C}_{3} \mathrm{~S}$, and the output variable of 28 day cement strength, were fuzzified by the use of ANNs, and triangular membership functions were employed for the fuzzy subsets. The model has been compared with the ANN model concerning level of errors and friendliness of use. Madsen et al. [28] presented some considerations related to fuzzy-genetic algorithms and specifically applied to a widely used cement type, CEM I. Tutmez and Dag [29] presented a linguistic model for predicting 28 day compressive strength of cement by making use of 1,3 and 7 days' strength values. Their model has been designed using fuzzy rules. A model developed by Yongzheng et al. belongs to the same class of models [30]. They used principal component analysis and ANN algorithms.

The majority of the models utilize results of cement produced in industry or laboratories aiming to estimate the corresponding model parameters. The minimum distance between experimental and computed strength is used as an optimization criterion. A potential disadvantage of some models is the requirement of additional analyses that usually are not made on a daily basis in industrial production. Implementation of such models in the daily quality control of cement plants is hardly found in the published literature. The predictions are accurate inside their field of application, i.e., for the given cement types, physical and chemical properties of cement and clinker and raw materials used. Therefore, there are no "universal" equations deriving sufficient predictions for any cement and clinker quality. Taking into account the above restrictions, the predictive models constitute extremely useful tools.

\section{Mathematical models predicting strength}

The modeling of 28 days cement strength is based exclusively on industrial data of cement produced in cement 
mill No. 6 (CM6) of Halyps Cement Plant during 6 years. Two cement types of different composition and strength are considered, conforming to the norm EN 197-1:2008: CEM II A-L 42.5 and CEM II B-M (P-L) 32.5. The first type, except clinker and gypsum, also contains limestone, whereas the second type contains pozzolane and limestone as main components. More than 1700 data sets of cement fineness, composition and strength were utilized for this purpose. The main cement constituents are computed using the average analysis of the raw materials: insoluble residue, loss on ignition ( $L O I)$, sulfates content $\left(\mathrm{SO}_{3}\right)$ using the algorithm presented in [31]. Two classes of models are developed: (1) the static ones, wherein for a given data set, the parameter values are computed through non-linear regression. Afterwards, these values are utilized to predict future strengths, each time the input data are available and (2) the models of movable horizon, where the parameters are estimated from a moving set of data belonging to a predefined past time interval, e.g., 3 months or 4 months, differing from the date of evaluation by at least 28 days.

\subsection{Static models}

Two types of static models (SMs) are derived. The dependent and independent variables of each model are shown in Table 1. The proposed models have the general form given by Eq. (9):

$$
Y=A_{0}+\sum_{I=1}^{N} A_{I} X_{I}+\sum_{I=1}^{N} A_{I I} X_{I}^{2}+\sum_{I=1}^{N} \sum_{J=I+1}^{N} A_{I J} X_{I} X_{J}
$$

where $X_{I}, X_{I}=$ the dependent variables, $Y=$ the independent variable and $N$ the number of independent variables. The coefficients $A_{I}, A_{I I}$ and $A_{I J}$ are determined by minimizing the residual error $s_{\text {res }}$ calculated by Eq. (10):

$$
s_{\text {res }}^{2}=\sum_{I=1}^{M} \frac{\left(Y_{\text {calc }}-Y_{a c t}\right)^{2}}{M-k}
$$

\begin{tabular}{llllll} 
Model & \%Clink & $\begin{array}{l}S_{b} / 10^{4} \\
\left(\mathrm{~cm}^{2} / \mathrm{g}\right)\end{array}$ & $R 40(\%)$ & $\begin{array}{l}\text { Str_1 } \\
(\mathrm{MPa})\end{array}$ & $\begin{array}{l}\text { Str_7 } \\
(\mathrm{MPa})\end{array}$ \\
\hline Str_28_1 & $\mathrm{X}$ & $\mathrm{X}$ & $\mathrm{X}$ & $\mathrm{X}$ & \\
Str_28_7 & $\mathrm{X}$ & $\mathrm{X}$ & $\mathrm{X}$ & $\mathrm{X}$ & $\mathrm{X}$ \\
\hline
\end{tabular}

Table 1 The dependent and independent variables of each model. $\%$ Clink, clinker content (\%); $S_{b}$, cement specific surface $\left(\mathrm{cm}^{2} / \mathrm{g}\right)$; $R 40$, residue at 40 microns sieve (\%); Str_ 1 and Str_7, compressive strengths after 1 and 7 days curing correspondingly (MPa);

Str_28_1,Str_28_7, 28 days strengths estimated from the first and second model, respectively. where $Y_{a c t}=$ actual 28 days strength, $Y_{\text {calc }}=$ the calculated one from the first or second model, $M=$ number of experimental sets, $k=$ number of independent variables for the first or second model. The full set of data involves all results of the two mentioned cement types from 2006 to 2011. This set is divided into five subgroups of data in a progressive way: data of (a) 2006-2007; (b) 2006-2008; (c) 2006-2009; (d) 2006-2010; (e) 2006-2011. To calculate the parameters of the first subgroup the subsequent procedure is followed:

(i) Initial values of the model parameters are determined using multiple regression for subset (a).

(ii) With the t-test and 95\% probability, the nonsignificant variables are excluded.

(iii) Steps (i) and (ii) are repeated iteratively until all coefficients of the resulting model become statistically significant.

(iv) Except for the residual error, $s_{r e s}$, the total variance of the experimental data is computed, $S_{T o t}{ }^{2}$ and the variance captured by the model, $S_{M o d}{ }^{2}$, given by Eq. (11).

$$
S_{M o d}{ }^{2}=S_{T o t}{ }^{2}-S_{\text {res }}^{2}
$$

Additionally, the percent of relative error, \%Error, is determined by the ratio of $s_{\text {res }}$ and average strength Str ${ }_{\text {Aver }}$ :

$$
\% \text { Error }=\frac{S_{\text {res }}}{S t r_{\text {Aver }}} \cdot 100
$$

(v) The model regression coefficient, $R_{M}$, is computed by Eq. (13):

$$
R_{M}=\frac{S_{M o d}}{S_{T o t}}
$$

(vi) For the parameters $\left(A_{I}, A_{I I}, A_{I}\right)$ computed from subgroup (a), multiple regression and steps (iv), (v) are repeated for the next subgroups (b), (c), (d) and (e).

The parameter values passing the t-test and the corresponding variances for the full set of data (e) are shown in Table 2. The parity plots of the two models are demonstrated in Figures 4 and 5.

\subsection{Movable time horizon models}

The static models suppose a relatively constant reactivity of the clinker or any other cement compound contributing to strength. No huge variances in the grinding process are 


\begin{tabular}{|c|c|c|}
\hline Coefficients $A_{p} A_{I P} A_{\| J}$ of variable & Str_28_1 & Str_28_7 \\
\hline Constant & 35.54 & 4.171 \\
\hline \%Clinker & -0.313 & \\
\hline$S_{b} / 10^{4}$ & 32.0 & 20.75 \\
\hline Str_1 & 1.075 & -0.067 \\
\hline Str_7 & & 0.914 \\
\hline$\%$ Clink $S_{b} / 10^{4}$ & & -0.420 \\
\hline \%Clink R40 & -0.014 & \\
\hline \%Clink Str_1 & 0.019 & \\
\hline$S_{b} R 40 / 10^{4}$ & 2.164 & -0.026 \\
\hline Str_1 Str_ 7 & & -0.013 \\
\hline$\%$ Clink $^{2}$ & $5.49 \times 10^{-3}$ & $3.05 \times 10^{-3}$ \\
\hline Str_ $1^{2}$ & -0.060 & 0.036 \\
\hline$s_{\text {res }}$ & 1.843 & 1.451 \\
\hline \%Error & 4.3 & 3.4 \\
\hline$R_{M}$ & 0.962 & 0.977 \\
\hline
\end{tabular}

Table 2 The parameter values of the models.

also presumed. In case these conditions are not fulfilled, then a noticeable probability exists that the static models fail to sufficiently predict the future cement strengths. To make this case manageable, models of movable time horizon concerning the introduced data are constructed. Similarly to the previous case, two categories of models are assumed, named Str_28_1 and Str_28_7, respectively. The independent and dependent variables are provided from Table 1. The structure of these models is a simplified form of Eq. (9), where coefficients $A_{I I}, A_{I J}$ are omitted. The algorithm of parameters determination operates as follows:

(i) At day $t$ a new 28 days strength result of cement produced in CM6 arrives. The specimen measured belongs to a sample prepared 28 days ago. The production date is in distance $t-29$ days from day $t$.

(ii) A time horizon $T$ in days is presumed. All the samples belonging to the period $[t-29-T, t-29]$ are considered. The movable data set contains this population of samples.

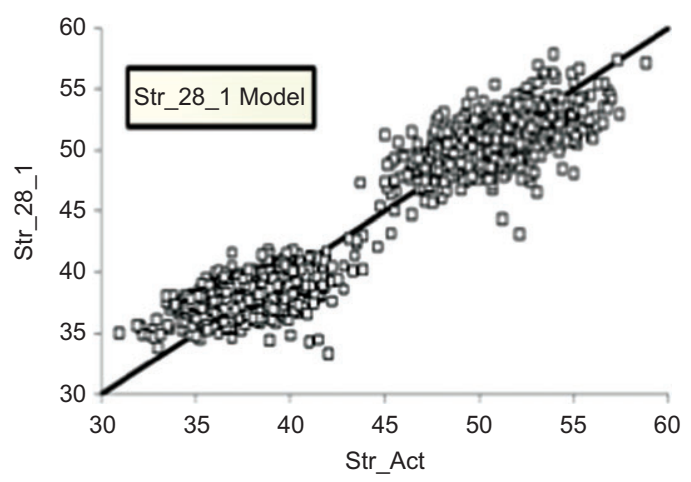

Figure 4 Calculated vs. actual values for the first model.

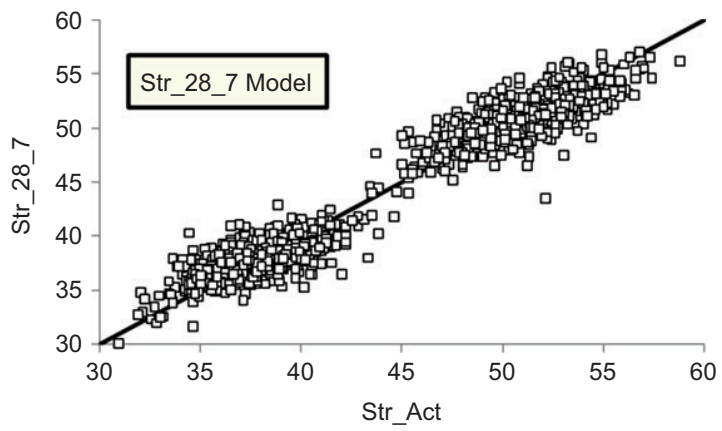

Figure 5 Calculated vs. actual values for the second model.

(iii) Using multiple regression, the model parameters $A_{I}$ $(I=0 . . . \mathrm{n})$ are estimated, as well as the residual error, $s_{\text {res }}$, model error, $s_{\text {Mod }}$ and regression coefficient, $R_{M}$.

(iv) At day $t$, the 1 day strength of the cement produced 2 days ago has been measured as well as the 7 days strength of cement produced 8 days ago.

(v) With the set of parameters computed in step (iii), the 28 days strength of cement produced at $t-2$ days and $t-8$ days are estimated, by applying the models Str_28_1 and Str_28_7, respectively.

The flexibility of the movable horizon models (MHMs) is due to their ability to compute the coefficients as a function of time, thus taking into account possible changes of the impact of factors with an impact on 28 days strength. As an example, the coefficients of \%Clinker and Str_1 for the first model are demonstrated in Figure 6. A time horizon $T=90$ days is chosen. The respective coefficients of \%Clinker and Str_7 are depicted in Figure 7. The residual errors as a function of time for the two models are shown in Figures 8 and 9, correspondingly. In the same figures the average residual error per model is shown.

The average residual errors of the movable horizon models are significantly lower than those of the respective

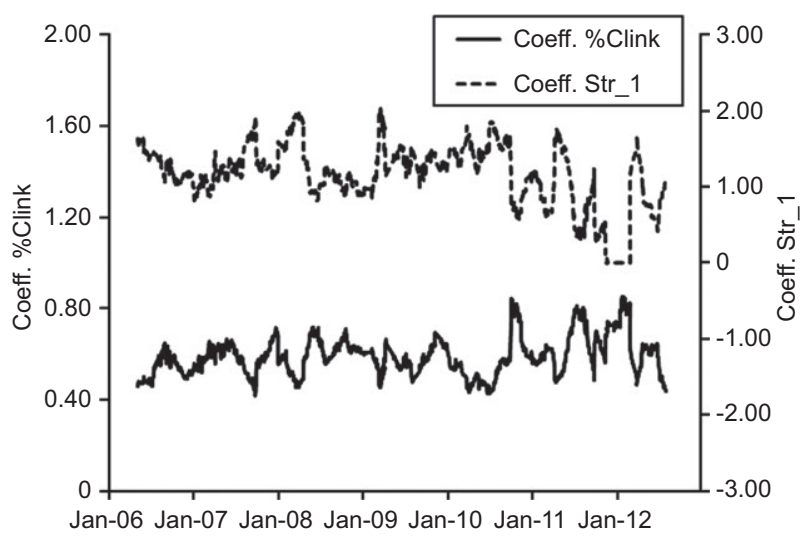

Figure 6 Coefficients of \%Clinker and Str_ 1 for the first model. 


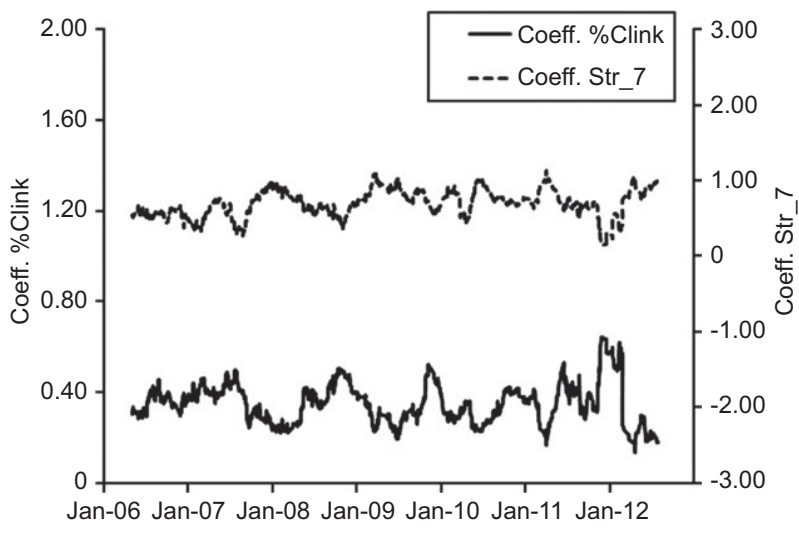

Figure 7 Coefficients of \%Clinker and Str_7 for the second model.

static models. The average relative errors, \%Error for SMs and MHMs for the full set of data are depicted in Table 3, where a visible decrease of the modeling error becomes apparent.

\section{Results and analysis}

\subsection{Implementation of the strength predicting models}

SM is constantly applied in Halyps Cement Plant in the long-term. To investigate the validity of SMs, the set of data has been divided into five subgroups (a)-(e), described in the previous section and the parameters are estimated for each one. The parameters of each subgroup are applied in the next year: parameters of subgroup (a) - years 2006-2007 - are applied to 2008 data. The above procedure has been applied continuously. Finally, the set of parameters of subgroup (d) are applied to 2011-2012

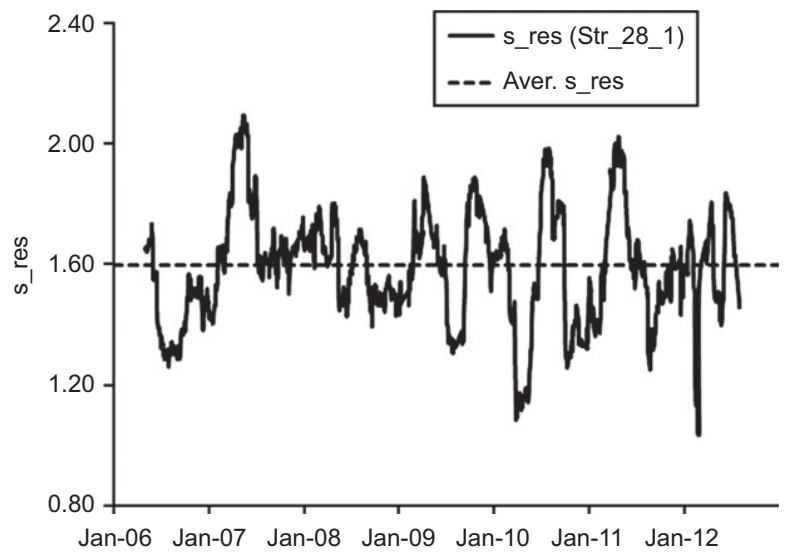

Figure 8 Residual errors for the first model.

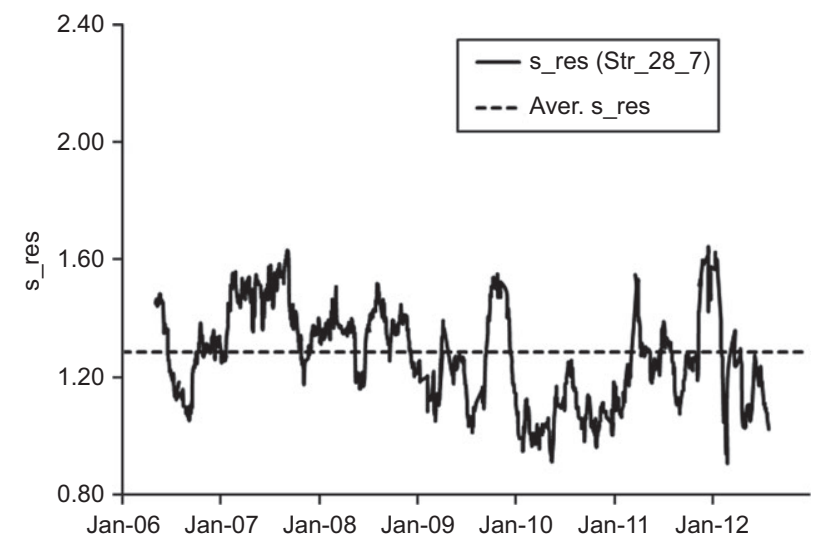

Figure 9 Residual errors for the second model.

data. In Tables 4 and 5, the following results are demonstrated for the first and second SMs, correspondingly: (i) residual error of each subset, $s_{\text {res }}$, and relative error, $\%$ Error; (ii) model regression coefficient $R_{M}$; (iii) residual error after the application during the next year, $s_{\text {next }}$ and relative error $\%$ Error $_{\text {next }}$; and (iv) the ratio $R_{s}=s_{\text {next }} / s_{\text {res }}$. In MHM, the parameters are continuously estimated after a new 28 days strength result appears. To facilitate the comparison, the MHM results are also presented in the same tables as follows: (i) residual error of each subset, $s_{\text {мнм}}$, and relative error, \%Error; (ii) model regression coefficient $R_{\text {MнM }}$; and (iii) the ratio $R_{\text {MHм/SM }}=S_{\text {MHM }} / s_{\text {next }}$.

From the SM results of Tables 4 and 5, the subsequent remarks can be made:

(a) The application of the first model to next year data results in an increase of $s_{\text {next }}$. The ratio $s_{\text {next }} / s_{\text {res }}$ is found within the zone $[1.05,1.62]$. Whereas the relative error, $\%$ Error, remains lower than $4 \%$ during the process of parameters estimation, the value of $\%$ Error $_{\text {next }}$ augments: in three out of four cases, it is higher than $4.5 \%$, reaching the non-acceptable value of $6.4 \%$.

(b) The second model is much more accurate compared with the first model as it takes into account the actual 7 days strength. Its implementation to next year data derives ratios $R_{s}$ ranging from 0.96 to 1.34 .

(c) Owing to the much bigger delay time of this model compared with the first model, generally it cannot

\begin{tabular}{llr} 
Model & SM & MHM \\
\hline Str_28_1 & 4.3 & 3.7 \\
Str_28_7 & 3.4 & 3.0 \\
\hline
\end{tabular}

Table $3 \%$ Error of SM and MHM. 


\begin{tabular}{|c|c|c|c|c|}
\hline $\begin{array}{l}\text { Parameters from data of } \\
\text { Applied to data of }\end{array}$ & $\begin{array}{r}2006-2007 \\
2008\end{array}$ & $\begin{array}{r}2006-2008 \\
2009\end{array}$ & $\begin{array}{r}2006-2009 \\
2010\end{array}$ & $\begin{array}{l}2006-2010 \\
2011-2012\end{array}$ \\
\hline \multicolumn{5}{|l|}{ Static model } \\
\hline$s_{\text {res }}$ & 1.62 & 1.65 & 1.67 & 1.71 \\
\hline$\%$ Error & 3.8 & 3.9 & 3.9 & 4.0 \\
\hline$R_{M}$ & 0.972 & 0.971 & 0.970 & 0.967 \\
\hline$s_{\text {next }}$ & 1.89 & 1.73 & 2.01 & 2.77 \\
\hline$\%$ Error $_{\text {next }}$ & 4.5 & 4.1 & 4.7 & 6.4 \\
\hline $\begin{array}{l}R_{s} \\
\text { Movable horizon model }\end{array}$ & 1.17 & 1.05 & 1.20 & 1.62 \\
\hline$s_{M H M}$ & 1.63 & 1.76 & 1.73 & 2.03 \\
\hline$\%$ Error & 3.8 & 4.2 & 4.1 & 4.6 \\
\hline$R_{\text {MHM } / S M}$ & 0.86 & 1.02 & 0.86 & 0.73 \\
\hline
\end{tabular}

Table 4 Results of model Str_28_1.

be utilized for direct control purposes. However, it can be used as additional information for cement composition adjustment.

(d) SMs adequately predict future strengths only if negligible or small changes to processes or to materials activity occur.

(e) For both SMs - Str_28_1, Str_28_7 - generally it can be concluded that as long as the bigger the distance between the time periods the parameters are determined and applied, thus the higher the application error is.

The movable horizon model overcame the partial weaknesses of the SM. The relative errors, \%Error, always remain significantly $<5 \%$ and $4 \%$ for Str_28_1 and Str_28_7 models, respectively. Thus, the ability to predict future 28 days strength is increasing to a substantial extent. The ratio of the residual errors between the MHM and SM, $R_{\text {MHM/SM }}$ is demonstrated in Figure 10. This ratio drops to values $<0.85$, indicating the higher performance of the MHM, in such cases where the SM parameters have not been updated using only recent data or there is a significant change in the grinding process or to materials reactivity. To obtain a more accurate prediction with MHM, a more complicated computational algorithm is needed in comparison with the one that has been constructed for SM. Achieving the highest performance means that MHM is applied any time a new result of 28 days strength arises or, in other words, the computation of new model parameters has to become a routine operation of the plant quality department.

\subsection{Control of compressive strength by applying the models}

The models predicting strength offer the possibility to build a controller regulating 28 days strength around a

\begin{tabular}{|c|c|c|c|c|}
\hline $\begin{array}{l}\text { Parameters from data of } \\
\text { Applied to data of }\end{array}$ & $\begin{array}{r}2006-2007 \\
2008\end{array}$ & $\begin{array}{r}2006-2008 \\
2009\end{array}$ & $\begin{array}{r}2006-2009 \\
2010\end{array}$ & $\begin{array}{l}2006-2010 \\
2011-2012\end{array}$ \\
\hline \multicolumn{5}{|l|}{ Static model } \\
\hline$s_{\text {res }}$ & 1.43 & 1.42 & 1.41 & 1.40 \\
\hline$\%$ Error & 3.4 & 3.3 & 3.3 & 3.3 \\
\hline$R_{M}$ & 0.979 & 0.979 & 0.979 & 0.978 \\
\hline$S_{\text {next }}$ & 1.52 & 1.36 & 1.45 & 1.87 \\
\hline$\%$ Error $_{\text {next }}$ & 3.6 & 3.2 & 3.4 & 4.3 \\
\hline$R_{s}$ & 1.06 & 0.96 & 1.03 & 1.34 \\
\hline \multicolumn{5}{|l|}{ Movable horizon model } \\
\hline$s_{\text {мнM }}$ & 1.42 & 1.39 & 1.23 & 1.57 \\
\hline$\%$ Error & 3.3 & 3.3 & 2.9 & 3.6 \\
\hline$R_{\text {MнM/SM }}$ & 0.93 & 1.02 & 0.85 & 0.84 \\
\hline
\end{tabular}

Table 5 Results of model Str_28_7. 


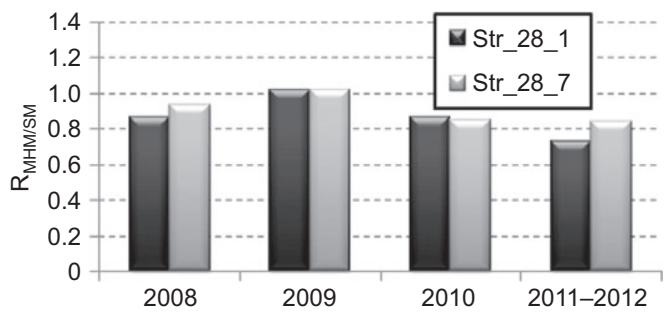

Figure 10 Ratio of residual errors of MHM and SM.

predefined target. A proportional-integral (PI) controller is designed. The moving average of the result of first model - Str_28_1=F(\%Clinker,Sb,R40,Str_1) - constitutes the controller input. Moving average is a filter of the Str_28_1 variable and it is computed according to the exponentially weighted moving average (EWMA) technique [32]. This variable, named EW_Str, is the process variable of the feedback loop. Clinker content, \%Clink, is the control variable. The control strategy is to regulate the $E W \_S t r$ variable in order to achieve a Str_28 of minimum variance around the target Str_T. The digital implementation of the controller equation is given by a set of formulae in Eq. (14). A weighting coefficient $\lambda=0.5$ is chosen.

$$
\begin{gathered}
C l_{\text {Instr(I+1) }}=C l_{\text {Instr }(I)}+\cdot k_{p} \cdot[e(J)-e(J-1)]+k_{i} \cdot e(J) \\
e(J)=S t r_{T}-E W_{S t r(I)} \\
E W_{S t r(J)}=\lambda \cdot \operatorname{Str}_{28_{1(J)}}+(1-\lambda) \cdot E W_{\operatorname{str}(J-1)}
\end{gathered}
$$

if $S_{t r}{ }_{1(I)}>0$ then $J=I$ else if $\operatorname{Str}_{1(I)}=0$ then $J=I-1$

where the last production date is $I$ and the next one is I+1. Cl_Inst $(I)=\%$ Clinker of the nominal composition of day $I$. If $I$ and $I+1$ are successive dates (e.g., 3 July and 4 July), Str_l(I) has not yet been measured at date $I+1$. In

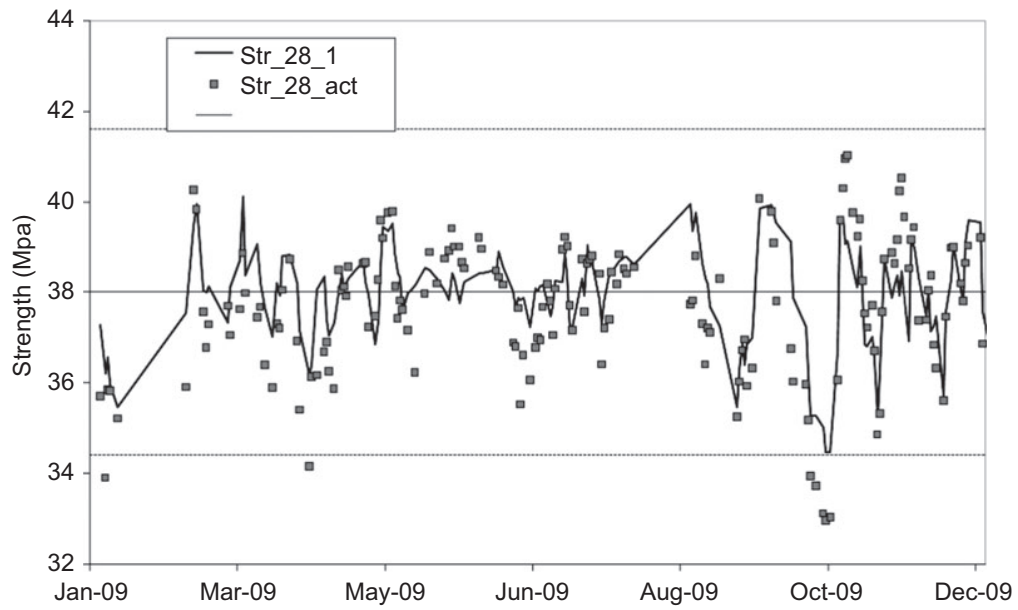

Figure 11 SM application for CEM BM 32.5 N.

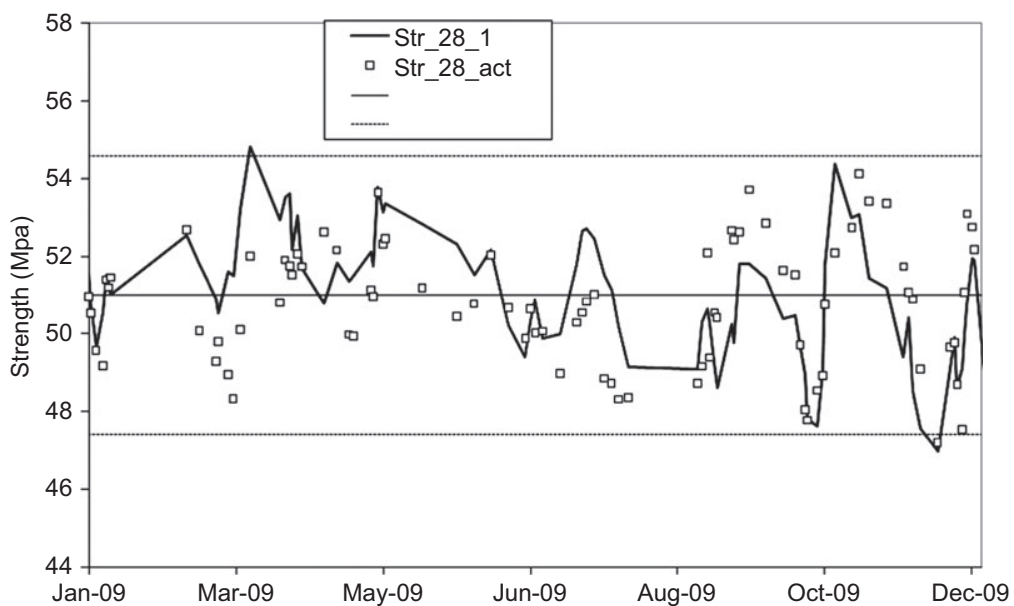

Figure $12 \mathrm{SM}$ application for CEM AL $42.5 \mathrm{~N}$. 
this case, $J=I-1$ and Str_28_1(I-1) is calculated using Eq. (9) and values of \%Clinker(I-1), $R 40(I-1), S b(I-1), S t r \_1(I-1)$. On the contrary if dates $I, I+1$ are discontinuous, then Str_1(I) exists and prediction Str_28_1(I) is determined from the corresponding physical, chemical and mechanical data. The proportional and integral coefficients of the controller are $k_{p}$ and $k_{i}$, respectively. The values of these two coefficients have been calculated with trial and error by simulating the controller operation using data of older years. For each time $J$, the error $e(J)$ between strength target, Str_T and moving average $E W_{-} S t r(J)$ is calculated and fed to the controller.

The combined action of the strength predicting models and PI controller are shown in Figures 11-14. In Figures 11 and 12, the strength data of 2009 are shown by implementing the static model for both cement types, whereas in Figures 13 and 14, the movable horizon model is continuously applied, regulating 28 days strength during 2011 and 2012. Owing to the efficient implementation of the analyzed techniques, 28 days strength varies in a span noticeably narrower than the one allowed by EN 197-1, which is $20 \mathrm{MPa}$. The above actions result in a good level of strength standard deviation.

\section{Conclusions}

The standard compressive strength at 28 days is the main cement feature characterizing the cement quality, having rigorous normative limits and it is widely used in the concrete mix design. Unfortunately, it is a long time for the cement industry to wait for 28 days to have the results of each lot of produced cement and afterwards to

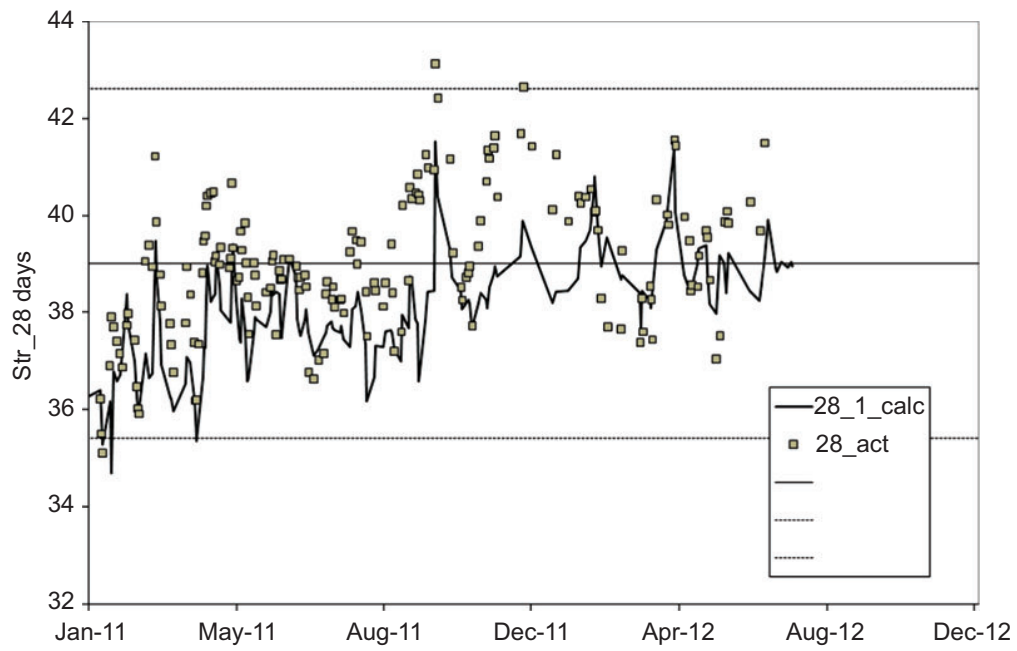

Figure 13 MHM application for CEM BM 32.5 N.

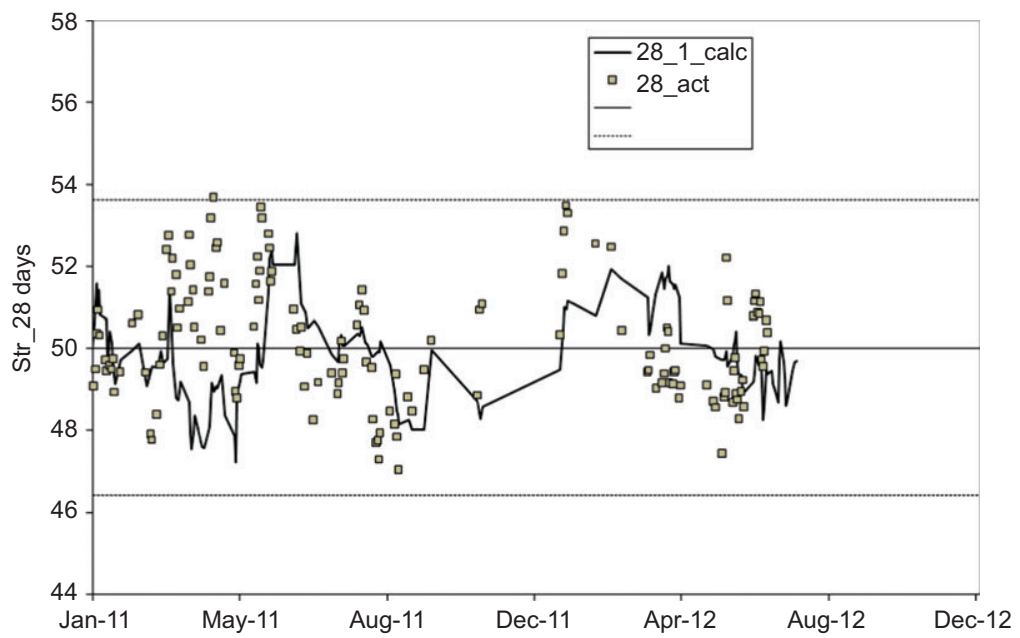

Figure 14 MHM application for CEM AL 42.5 N. 
sell it. If, for example, a cement plant sells 10 kton of a certain cement type daily, then it has to have 280 kton of stock capacity only for this cement type, or more than 20 silos of 15 kton capacity each. A tool assisting in avoiding such a situation, which usually cannot be realized at all, is the prediction of the typical 28 days strength from early strength results as well as from chemical and physical cement characteristics. A relatively extended summary of this type of model was presented in this paper. The predictions are accurate inside their field of application, i.e., for the given cement types, and the studied ranges of physical and chemical characteristics of cement.

In the present study, two categories of models have been presented: (a) the static ones, where based on a predetermined data set, the parameters values are computed and are utilized to predict the future strengths and (b) the models of movable time horizon, where the parameters are estimated from a moving set of data belonging to a predefined past time interval. The entire industrial data of cement produced in CM6 of Halyps Cement Plant during 6 years have been used. Two cement types are considered, conforming to the norm EN 197-1:2008: CEM II A-L 42.5 and CEM II B-M (P-L) 32.5. The future strength predictions obtained by the static models are sufficient only if negligible or small changes to the processes or to the materials activity occur. The movable horizon model overcomes the partial weaknesses of the static model with the cost of a more complicated algorithm and additional time needed for its daily implementation. The strength predictions provide the possibility to develop simple PI controllers acting on cement composition and regulating 28 days strength. The long-term implementation of these techniques has been noticeably contributing to improving cement quality by maintaining a low variance of typical strength.

With the aim of ameliorating the tools applied daily in quality control of a cement plant, the analysis presented can be deepened in subsequent fields.

- Optimization of the movable horizon model concerning the time interval. This procedure probably needs a case-by-case study, related to the run factor of the cement mill under investigation.

- Deeper investigation of the control charts techniques in monitoring of cement properties and further utilization of filters to smooth the trends.

- Parameterization of PI or proportional integral derivative (PID) controllers using methodologies taking into account both robustness and performance of the control.

\section{References}

[1] Meyer D. J. Appl. Math. Decis. Sci. 1997, 1, 89-100.

[2] Tango CES. Proceedings of the International Symposium on High Performance Concrete. Leung CK, Li Z, Ding J, Eds. Hong Kong, China, 2000.

[3] Novokshchenov V, Al-Mudhaf H, Al-Fadhala M. Mater. Struct. 2006, 30, 112-119.

[4] Tsamatsoulis D. Proceedings of 16th WSEAS International Conference on Systems. Balas VE, Koksal M, Eds. WSEAS Press: Kos Island, Greece, 2012, pp. 136-145.

[5] Lee FM. The Chemistry of Cement and Concrete, 3rd ed., Chemical Publishing Company: New York, 1971, pp. 164-165, 171-174, 384-387.

[6] Duda WH. Cement Data Book, 3rd ed., Bauverlag GmbH: Berlin, 1985, Vol. 1, pp. 117-301.

[7] Bogue RH. The Chemistry of Portland Cement, 2nd ed., Reinhold Publishing Corporation: New York, 1955, pp. 245-268.

[8] Odler I. Mater. Struct. 1991, 24, 143-157.

[9] Sideris K. The cement hydration equation. Zement Kalk Gips, Edition B, 1993, 337-344.

[10] De Siqueira Tango CE. Cem. Concr. Res. 1998, 28, 969-983.

[11] Tsivilis S, Parissakis G. Cem. Concr. Res. 1995, 25, 9-14.

[12] Kheder GF, Gabban AM, Abid SM. Mater. Struct. 2003, 36, 693-701.

[13] Abd SM, Zain MFM, Abdul Hamid R. Proceedings of International Conference on Construction and Building Technology, Al-Mattarneh H, Fauzi Mohd Zain M, Al-Gadhib AH, Eds. International Association of Concrete Technology, University Publication Centre: Kuala Lumpur, 2008, pp. 343-354.

[14] Kostogloudis GCh, Kasselouri V, Philippou Th, Ftikos Ch. Proceedings of the International Congress "Creating with Concrete”. Dhir RK, Hewlett PC, Jones MR, Eds. Tomas Telford Publishing: London, Dundee, UK, 1999.

[15] Relis M, Ledbetter WB, Harris P. Cem. Concr. Res. 1988, 18, 674-686.

[16] García-Casillas PE, Martinez CA, Montes H, García-Luna A. Mater. Manuf. Process. 2007, 22, 333-336.

[17] Svinning K, Høskuldsson A, Justnes H. Cem. Concr. Comp. 2008, 30, 138-151.

[18] Svinning K, Høskuldsson A, Justnes H. Cem. Concr. Comp. 2010, 32, 300-311.

[19] Mechling JM, Lecomte A, Diliberto C. Cem. Concr. Comp. 2009, 31, 255-262.

[20] Phatak DR, Deshpande NP. J. Mater. Civ. Eng. 2005, 17, 733-735.

[21] Çolak A. Cem. Concr. Res. 2006, 36, 1409-1413.

[22] Zelić J, Rušić D, Krstulović R. Cem. Concr. Res. 2004, 34, 2319-2328. 
[23] Tsamatsoulis D. WSEAS Trans. Syst. 2009, 8, 1166-1176.

[24] Gao FL. Cem. Concr. Res. 1997, 27, 883-888.

[25] Akkurt S, Ozdemir S, Tayfur G, Akyol B. Cem. Concr. Res. 2003, 33, 973-979.

[26] Baykasoğlu A, Dereli T, Tanış S. Cem. Concr. Res. 2004, 34, 2083-2090.

[27] Akkurt S, Tayfur G, Can S. Cem. Concr. Res. 2004, 34, 1429-1433.

[28] Madsen M, Thyregod P, Popentiu F, Albeanu G, Coarna M, Serbanescu L, Mirza D, Tautan A. Proceedings of the 9th World Multi-Conference on Systemic, Cybernetics and Informatics. Zinn ID, Savoie MJ, Lin KC, El-Badawy E, Benga G, Eds.
International Institute of Informatics and Systemics: Orlando, FL, USA, 2005, pp. 350-353.

[29] Tutmez B, Dag A. Mater. Struct. 2009, 42, 103-111.

[30] Yongzheng Z, Biyun X, Yong Z. Proceedings of IEEE 3rd International Conference on Communication Software and Networks (ICCSN). Institute of Electrical and Electronics Engineers: Xi'an, 2011, pp. 238-241.

[31] Tsamatsoulis D. 14th Greek Congress of Concrete. Vadaloukas G, Giaka A, Thodoropoulou P, Eds. Technical Chamber of Greece: 2003, pp. 263-270.

[32] Newubauer A. Clin. Chem. 1997, 43, 594-601. 